\title{
Studies on the development of a vaginal preparation providing both prophylaxis against venereal disease and other genital infections and contraception
} II- Effect in vitro of vaginal contraceptive and
non-contraceptive preparations on Treponema
pallidum and Neisseria gonorrhoeae

\author{
BALWANT SINGH, JOHN C. CUTLER, AND H. M. D. UTIDJIAN \\ Graduate School of Public Health, University of Pittsburgh, Pennsylvania 15213, U.S.A.
}

Since 1956, when the incidence of infectious syphilis and gonorrhoea began to rise following its marked decrease after World War II, the upward trend has continued with little variation to the present time. In the U.S.A., of the reportable infectious diseases, syphilis and gonorrhoea combined are second only to influenza and far exceed streptococcal sore throat, tuberculosis, poliomyelitis, and other diseases which are now commonly regarded as a threat to mankind (Webster, 1970). Gonorrhoea is now in the epidemic state not only in the United States, but in many countries throughout the world. It has long been recognized that the actual number of cases of venereal disease (V.D.) is much greater than that reported by physicians; in the United States only 10 per cent. of cases of V.D. are reported, according to a nationwide study done by the American Social Health Association (1969), and in some urban areas one out of every ten of the sexually active population acquires gonorrhoea annually (Kraus and Webster, 1971). Other diseases known to be transmitted during sexual intercourse, such as scabies and pediculosis pubis, are said to be increasing in frequency. It has been contended that the removal of fear of pregnancy by the increasing availability and use of oral contraceptive pills and intrauterine devices has contributed to the increase of promiscuous sexual activity, and has thus possibly become a new factor facilitating the spread of V.D. (Idsøe and Guthe, 1967). Another factor is that changes in cthical, moral, and behavioural codes are taking place-the so-called 'sexual revolution'. Venereal disease and unwanted pregnancy alone or together may result from unprotected sexual intercourse, and it is hypothesized that the use

Received for publication June 30, 1971 of an intravaginal contraceptive preparation combined with an intravaginal agent for prevention of infection would simultaneously reduce the frequency of both conditions. Considering the importance of this matter, we have undertaken a research project as described previously (Cutler, Utidjian, Singh, and Arnold, 1971).

The study described here is our first report on laboratory work directed to a search for a combined agent with contraceptive and prophylactic properties.

\section{Material and methods}

Most of the preparations tested in this study were purchased directly from the market. Some of the products were received from the manufacturers in response to requests by letter. The various tests used for this study were adopted from the United States Food and Drug Administration Methods for Testing Antiseptics and Disinfectants (1931). Dilutions of various preparations were made in physiological saline solution and unless otherwise specified, a mechanical mixer (Vortex) was used for proper mixing and for preparing the serial dilutions.

\section{Harvest of spirochaetes}

A rabbit infected with pathogenic Treponema pallidum (Nichols strain) received from the Venereal Disease Research Laboratory, Center for Disease Control, Atlanta, Georgia, provided the source of the strain which has been maintained by regular passage in rabbits for subsequent testing. At the peak of acute orchitis, the rabbit is killed by injecting air into the ear vein. The testicles are removed aseptically, sliced, and minced into small pieces. Physiological saline solution with 20 per cent. rabbit serum is added in a quantity of $15-20 \mathrm{ml}$. for each pair of testicles. The spirochaetes are extracted by shaking the flask for $1 \frac{1}{2}$ hours, using a low-speed mechanical shaker at room temperature. Then the material is centrifuged for 15 minutes at $110 \times \mathrm{G}$ and the supernatant suspension of treponemes is removed. The harvest 
is considered satisfactory for the test if ten or more actively motile spirochaetes are present per $40 \times$ darkfield in each of five different fields. For regular passage and maintenance of $T$. pallidum, 0.2 to $0.5 \mathrm{ml}$. of the spirochaete harvest is injected by the intratesticular route into a healthy normal rabbit. The next spirochaete harvest from the injected rabbit is made in about 11 days at the time of acute orchitis.

\section{TECHNIQUE FOR TESTING SPIROCHAETICIDAL EFFECT}

The spirochaeticidal property of various test samples was studied according to the previously reported methods of Arnold and Cutler (1956) as well as those of Turner, Hollander, and Schaeffer (1953). Each test sample was diluted to $50,20,10$ and 1 per cent. concentrations (weight/volume) with physiological saline. For preliminary screening, one drop of $T$. pallidum suspension was placed on the microscope slide next to one drop of the diluted test sample. The two drops were mixed with an applicator stick and the stop-clock was started for timing. The coverslip was then placed and the slide was examined by darkfield microscopy. The time required to immobilize spirochaetes was noted and recorded. 1 to 1.5 minutes were required for the preparation and thorough darkfield examination of the five different fields of each wet smear slide; accordingly the dilutions of the test sample that were effective in rendering the spirochaetes non-motile within 1 to 1.5 minutes were further tested. For this purpose a more quantitative method was used in which $0.5 \mathrm{ml}$. $T$. pallidum suspension was mixed with an equal volume of diluted test sample. At various intervals slides were prepared and examined for the motility of spirochaetes. The time required for the immobilization with each dilution was recorded. Physiological saline solution was used as a control and the number of spirochaetes and their motility was recorded at the end of the experiment. The $p H$ of the saline control solution was adjusted with $1 \mathrm{~N} \mathrm{HCl}$ or $\mathrm{NaOH}$ to that of the test sample.

\section{Neisseria gonorrhoeae CULTURE}

For preliminary studies the isolates of $N$. gonorrhoeae from the local Health Department V.D. Clinic were used. However, for the purpose of this study, a stock culture was prepared by lyophilizing a bacterial suspension which was obtained from 24-hour-old bacterial colonies by washing with Trypticase Soy Broth (BBL) containing 10 per cent. rabbit serum. Micro-organisms were grown on chocolate agar or Thayer-Martin (TM) selective medium in a $\mathrm{CO}_{2}$ incubator at $37^{\circ} \mathrm{C}$. The plates of Thayer-Martin medium were prepared and used as described by Thayer (1970). The inoculum was prepared by washing a 24-hour culture from one plate with $1 \mathrm{ml}$. Trypticase Soy Broth and adding additional broth to bring it to a standard density $60 \pm 5$ per cent. transmission as determined by Colorimeter, $\mathrm{B}$ and $\mathrm{L}$ spectronic ' 20 ' at $620 \mathrm{~m} \mu$. The total number of micro-organisms was also determined by the standard plate dilution method on TM medium. $N$. gonorrhoeae cultures were identified by the oxidase test and Gram-staining and were confirmed by sugar fermentation test.
TECHNIQUE FOR TESTING BACTERICIDAL EFFECT

Two methods were used for determining the bactericidal and bacteriostatic effect of test samples on $N$. gonorrhoeae cultures. Undiluted, and 50, 20, 10, and 1 per cent. (W/V) concentrations of contraceptives and vaginal antiseptics were prepared and tested as follows. In preliminary studies the chocolate agar and the TM selective medium were compared. The same results were obtained by using these two media, but because several products were found contaminated as originally received in jars from different companies, it was decided to use TM selective medium.

\section{(a) Time exposure method}

To $1 \mathrm{ml}$. of various dilutions of test samples of the preparation under study, $0.1 \mathrm{ml}$. of bacterial culture suspension containing $10^{5}$ to $10^{6}$ organisms was added and mixed. After intervals of 1,5 , and 10 minutes, the mixture was inoculated by streaking on TM selective medium plates, using a 3-mm. wire loop. The plates were incubated in a $\mathrm{CO}_{2}$ incubator at $37^{\circ} \mathrm{C}$. and read after 24 hours. The concentration of test material which completely inhibited the visible growth of $N$. gonorrhoeae after the period of exposure was taken as the effective concentration for this exposure interval.

\section{(b) Plate dilution method}

$1 \mathrm{ml}$. of each dilution of the test sample was added to $9 \mathrm{ml}$. of melted TM medium at about $50^{\circ} \mathrm{C}$., mixed, and poured into $60 \times 15 \mathrm{~mm}$. Petri dishes. After the plates were dry, they were inoculated by streaking with a 3-mm. wire loop from a bacterial suspension containing $10^{5}$ to $10^{6}$ Colony Forming Units (CFU) per $0.1 \mathrm{ml}$. The plates were incubated in a $\mathrm{CO}_{2}$ incubator at $37^{\circ} \mathrm{C}$. and read after 24 hours. The lowest concentration of test material completely inhibiting the visible bacterial growth was considered the end-point.

\section{Results}

EFFECT ON MOTILITY OF $T$. pallidum

Twenty contraceptive and seventeen non-contraceptive vaginal antiseptic preparations were tested for their spirochaeticidal effects on $T$. pallidum in vitro. The results in Table I show the effective concentration of contraceptives which inhibited the motility of actively motile $T$. pallidum. As shown in Table I the various contraceptives are grouped according to the concentrations required to immobilize spirochaetes within 1 to 1.5 minutes. Only two contraceptives were effective at 1 per cent. concentration and were placed in Group A. The $p H$ of these two contraceptives at 1 per cent. concentration were 6.2 and $7 \cdot 1$ respectively. Group $B$ included twelve different contraceptives all of which were effective at 10 per cent. concentration. The $p H$ alone within this range was not responsible for reducing the motility of spirochaetes as judged by the controls in this range. Three contraceptives (Group C) were effective at 
TABLE I Dilutions of contraceptives required to immobilize T. pallidum suspension within 1 to 1.5 minutes

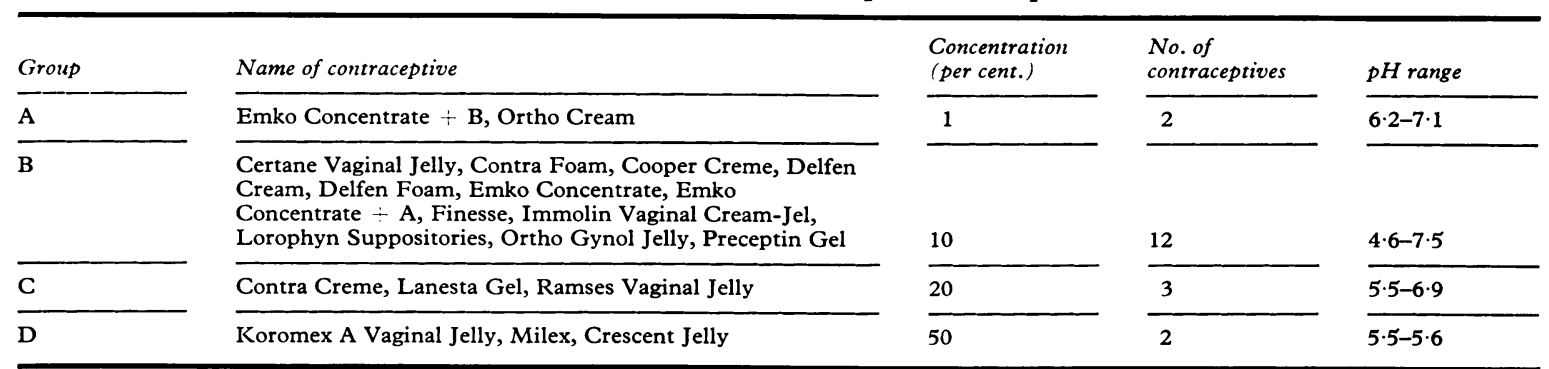

*Control from $p \mathrm{H} 4.6$ to 7.5 did not immobilize spirochaetes in 5 minutes

20 per cent. concentration and two at 50 per cent. (Group D).

The results with non-contraceptive preparations tested for this purpose are shown in Table II. Several of these test samples were to be found to be spirochaeticidal by the criterion of motility.

Nine preparations (non-contraceptive Group B) out of seventeen immobilized spirochaetes within 1 to 1.5 minutes. The $p H$ of test samples in Group B ranged from 3.5 to $7 \cdot 2$. The more alkaline preparations, with the exception of one (Group E), were effective at high dilution ( 1 per cent.) as show $\mathbf{n}$ in Group A; the $p \mathrm{H}$ of two preparations was 8.8 and $9 \cdot 4$.

\section{EFFECT ON GROWTH OF $N$. gonorrhoeae}

All these contraceptives and other preparations were tested for their inhibitory effect on the growth of $N$. gonorrhoeae. Two types of tests were used for this study and results are shown in Table III and IV for contraceptives and non-contraceptives respectively.

In the time-exposure test, in which a bacterial suspension was mixed with the test sample and after 1,5 , and 10 minutes, the TM selective medium plates were inoculated from the mixture, only three contraceptives (Nos 4, 17, and 19) at 1 per cent. dilution inhibited the bacterial growth (Table III). Two preparations (Nos 4 and 19) were effective in inhibiting the bacterial growth even after 1 minute exposure. Eight of the contraceptives were effective at 10 per cent. concentration, but some of these required 5 or 10 minutes contact to inhibit the bacterial growth.

By the plate-dilution method, in which dilutions of the test sample were incorporated into the $T M$ selective medium, two preparations were effective at 1 per cent. concentration and eleven were effective at 10 per cent. dilution (approximately 1 per cent. final concentration in the growth medium). The $p \mathrm{H}$ of the medium was $7 \cdot 2 \pm 0.2$ and did not change significantly after addition of the diluted test sample.

The time-exposure technique was found to be the more sensitive of these two methods. In most cases the contraceptive dilution which was effective by the time-exposure technique was also effective by the plate-dilution method. However, with the exception of two preparations (Nos 4 and 13), a low concentration of contraceptives was required for inhibiting the bacterial growth by the time-exposure method as compared to the plate dilution.

Several non-contraceptive preparations were also found effective (Table IV). Again, with the exception of some samples, the dilutions which were effective by time-exposure also inhibited growth by plate-

TABLE II Dilutions of non-contraceptives required to immobilize T. pallidum suspension within 1 to 1.5 minutes $\star$

\begin{tabular}{|c|c|c|c|c|}
\hline Group & Name of non-contraceptive & $\begin{array}{l}\text { Concentration } \\
\text { (per cent.) }\end{array}$ & $\begin{array}{l}\text { No. of } \\
\text { contraceptives }\end{array}$ & pH range \\
\hline A & Neo-Silvol, Silver Protein, Vagisec Liquid Douche & 1 & 3 & $6 \cdot 8-9 \cdot 4$ \\
\hline C & Koromex A Base only, Trimo San Vaginal Jelly & 20 & 2 & $5 \cdot 6-5 \cdot 8$ \\
\hline E & Iso-Sol Argyrol & 100 & 1 & $8 \cdot 5$ \\
\hline
\end{tabular}

*Control from $p \mathrm{H} 3.5$ to 9.4 did not immobilize spirochaetes in 5 minutes 
TABLE II I Highest dilution of 20 contraceptives required to inhibit the growth of $\mathrm{N}$. gonorrhoeae by two methods ${ }^{2}$

\begin{tabular}{|c|c|c|c|c|c|c|c|c|c|}
\hline \multirow{3}{*}{ No. } & \multirow{3}{*}{ Contraceptive } & \multicolumn{5}{|c|}{ Time-exposure method } & \multicolumn{3}{|c|}{ Plate-dilution method } \\
\hline & & \multirow{2}{*}{$\begin{array}{l}\text { Concent- } \\
\text { ration } \\
\text { (per cent.) }^{b}\end{array}$} & \multirow{2}{*}{$p H$} & \multicolumn{3}{|c|}{$\begin{array}{l}\text { Growth after exposure } \\
\text { (min.) }\end{array}$} & \multirow{2}{*}{$\begin{array}{l}\text { Concent- } \\
\text { ration } \\
\text { (per cent.) }\end{array}$} & \multirow{2}{*}{$p H^{\mathrm{c}}$} & \multirow{2}{*}{ Growth $^{\mathrm{d}}$} \\
\hline & & & & 1 & 5 & 10 & & & \\
\hline 1 & Certane Vaginal Jelly & 10 & $4 \cdot 6$ & + & - & - & 10 & $7 \cdot 5$ & - \\
\hline 2 & Contra Creme & 50 & 6.9 & + & it & - & 10 & $7 \cdot 5$ & - \\
\hline 3 & Contra Foam & 10 & $7 \cdot 5$ & i: & - & - & 10 & $7 \cdot 5$ & - \\
\hline 4 & Cooper Creme & 1 & $6 \cdot 7$ & - & - & - & 10 & $7 \cdot 6$ & - \\
\hline 5 & Delfen Cream & 20 & $5 \cdot 2$ & + & + & + & 10 & $7 \cdot 6$ & - \\
\hline 6 & Delfen Foam & 50 & 4.9 & - & - & - & 20 & $7 \cdot 6$ & - \\
\hline 7 & Emko Concentrate & 50 & $7 \cdot 4$ & - & - & - & 20 & $7 \cdot 5$ & - \\
\hline 8 & Emko Concentrate $+\mathbf{A}$ & 50 & $7 \cdot 1$ & - & - & - & 20 & $7 \cdot 2$ & - \\
\hline 9 & Emko Concentrate $+\mathbf{B}$ & 50 & $7 \cdot 2$ & - & - & - & 20 & $7 \cdot 2$ & - \\
\hline 10 & Emko Concentrate + Spermicide & 20 & $7 \cdot 0$ & + & + & - & 20 & $7 \cdot 3$ & - \\
\hline 11 & Emko Foam & 10 & $7 \cdot 3$ & - & - & - & 10 & $7 \cdot 4$ & - \\
\hline 12 & Immolin Vaginal & 50 & 4.9 & - & - & - & 10 & $7 \cdot 5$ & - \\
\hline 13 & Koromex A Vaginal Jelly & 10 & $6 \cdot 0$ & + & - & - & 50 & $7 \cdot 5$ & - \\
\hline 14 & Lanesta Gel & 10 & $5 \cdot 6$ & + & - & - & 10 & $7 \cdot 5$ & - \\
\hline 15 & Lorophyn Suppositories & 10 & $5 \cdot 7$ & + & - & - & 10 & $7 \cdot 5$ & - \\
\hline 16 & Milex Crescent & 10 & $5 \cdot 7$ & - & - & - & 10 & $7 \cdot 5$ & - \\
\hline 17 & Ortho Creme & 1 & $6 \cdot 2$ & + & - & - & 1 & $7 \cdot 4$ & - \\
\hline 18 & Ortho-Gynol Jelly & 10 & $5 \cdot \overline{5}$ & + & - & - & 10 & $7 \cdot 4$ & - \\
\hline 19 & Preceptin Gel & 1 & 5.6 & - & - & - & 1 & $7 \cdot 4$ & - \\
\hline 20 & Ramses Vaginal & 50 & 6.7 & + & + & - & 50 & $7 \cdot 5$ & - \\
\hline
\end{tabular}

Bacterial suspension for these experiments contains about $10^{\circ} \mathrm{CFU}$ per $0.1 \mathrm{ml}$., the inoculated Thayer-Martin selective medium plates were incubated at $37^{\circ} \mathrm{C}$. in $\mathrm{CO}_{2}$ incubator

'Only $50,20,10$, and 1 per cent. dilutions in physiological saline solution were tested

epH of media after adding the contraceptive at different concentrations

dResults from duplicate plates

TABLE IV Highest dilution of 17 non-contraceptive preparations required to inhibit the growth of N. gonorrhoeae by two methods ${ }^{\mathrm{a}}$

\begin{tabular}{|c|c|c|c|c|c|c|c|c|c|}
\hline \multirow{3}{*}{ No. } & \multirow{3}{*}{ Preparation } & \multicolumn{5}{|c|}{ Time-exposure method } & \multicolumn{3}{|c|}{ Plate-dilution method } \\
\hline & & \multirow{2}{*}{$\begin{array}{l}\text { Concent- } \\
\text { ration }^{\mathrm{b}} \\
\text { (per cent.) }\end{array}$} & \multirow{2}{*}{$p H$} & \multicolumn{3}{|c|}{$\begin{array}{l}\text { Growth after exposure } \\
\text { (min.) }\end{array}$} & \multirow{2}{*}{$\begin{array}{l}\text { Concent- } \\
\text { ration } \\
\text { (per cent.) }\end{array}$} & \multirow{2}{*}{$p H^{\mathrm{c}}$} & \multirow{2}{*}{ Growth $^{\mathrm{d}}$} \\
\hline & & & & 1 & 5 & 10 & & & \\
\hline 1 & Betadine Vaginal Gel & 10 & $3 \cdot 7$ & - & - & - & 20 & $7 \cdot 6$ & - \\
\hline \multirow[t]{2}{*}{$\begin{array}{l}2 \\
3\end{array}$} & $\begin{array}{l}\text { Candeptin Vaginal Tablets } \\
\text { Emko Concentrate No Active }\end{array}$ & 50 & $6 \cdot 9$ & + & + & + & 50 & $7 \cdot 6$ & + \\
\hline & Ingredient & 10 & $7 \cdot 2$ & - & - & - & 10 & $7 \cdot 5$ & - \\
\hline 4 & Iso-sol Argyrol & 50 & $8 \cdot \overline{5}$ & - & - & - & 1 & $7 \cdot 3$ & - \\
\hline 5 & Koromex A Base only & 50 & $5 \cdot 3$ & + & + & + & 50 & $7 \cdot 6$ & - \\
\hline 6 & Neo-Silvol & 10 & 6.9 & + & - & - & & & \\
\hline 7 & Penigin & 1 & $4 \cdot 6$ & + & - & - & 1 & $7 \cdot 6$ & - \\
\hline 8 & Penigin C & 1 & 4.5 & - & - & - & 1 & $7 \cdot 4$ & - \\
\hline 9 & Progonasyl & 50 & $7 \cdot 7$ & - & - & - & 10 & $7 \cdot 4$ & - \\
\hline 10 & Propion Gel & 50 & $6 \cdot 6$ & + & - & \pm & 50 & $7 \cdot 0$ & + \\
\hline 11 & Silver Protein & 5 & $9 \cdot 5$ & - & - & $\overline{-}$ & 1 & $7 \cdot 3$ & - \\
\hline 12 & Sporostacin Vaginal Cream & 50 & $3 \cdot 0$ & \pm & - & - & 10 & $7 \cdot 3$ & - \\
\hline 13 & Trib Vaginal Cream & 50 & $5 \cdot 3$ & $\overline{ \pm}$ & - & - & 20 & $7 \cdot 4$ & - \\
\hline 14 & Trimo San Vaginal Jelly & 50 & $4 \cdot 6$ & + & - & - & 10 & $7 \cdot 4$ & - \\
\hline 15 & Vabal D Base & 50 & $4 \cdot 8$ & + & + & + & 50 & $7 \cdot 4$ & - \\
\hline 16 & Vabal D Cream & 20 & $5 \cdot 7$ & + & - & - & 10 & $7 \cdot 5$ & - \\
\hline 17 & Vagisec Liquid Douche & 50 & $9 \cdot 2$ & + & + & + & 50 & $7 \cdot 3$ & - \\
\hline
\end{tabular}


dilution. Only one preparation (No. 1) was found more effective by the time-exposure method.

The effect of exposure of $N$. gonorrhoeae to the different $p \mathrm{H}$ ranges encountered with contraceptive and noncontraceptive preparations was studied by adjusting the $p \mathrm{H}$ of physiological saline with $1 \mathrm{~N}$ $\mathrm{HCl}$ or $\mathrm{NaOH}$. The results are shown in Table $\mathrm{V}$; the growth of gonococci was not inhibited by exposure for up to 10 minutes in acid or alkaline $p \mathrm{H}$ from 3.0 to $10 \cdot 5$. However, the test micro-organisms were not viable after exposure for more than 1 minute at $p \mathrm{H} 2 \cdot 5$.

TABLE $\mathrm{V}$ Effect of $p H$ on viability of Neisseria gonorrhoeae in physiological saline solution

\begin{tabular}{|c|c|c|c|c|}
\hline \multirow{2}{*}{ Sample No. } & \multirow{2}{*}{$p \mathrm{H}$} & \multicolumn{3}{|c|}{ Growth ${ }^{\mathrm{a}}$ after exposure (min.) } \\
\hline & & 1 & 5 & 10 \\
\hline 1 & 2.5 & $\div$ & - & - \\
\hline 2 & 30 & - & + & + \\
\hline 3 & 35 & + & + & + \\
\hline 4 & $5 \cdot 5$ & $\therefore$ & + & + \\
\hline 5 & 6.9 & $\leftarrow$ & $\leftarrow$ & + \\
\hline 6 & $7 \cdot 6$ & + & + & + \\
\hline 7 & $9 \cdot 2$ & + & + & + \\
\hline 8 & 9.9 & + & $\div$ & + \\
\hline 9 & $10 \cdot 5$ & + & + & + \\
\hline Control & $6 \cdot 8$ & + & $\div$ & + \\
\hline
\end{tabular}

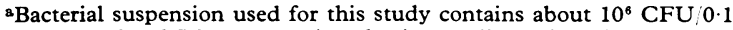
$\mathrm{ml}$. Inoculated Thayer-Martin selective medium plates incubated at $37^{\circ} \mathrm{C}$. in $\mathrm{CO}_{2}$ incubator

\section{Discussion}

The increase in incidence of venereal infection during recent years has created a challenge. Many of the control methods that are used routinely for other diseases are not easily adapted to venereal diseases. It is very evident that diseases of this nature cannot be reduced by effective therapy alone; prophylactic methods are necessary in addition for prevention and control.

With the foregoing in mind, and the fact that extensive testing, including some years of observation, is required for a new product to be approved for use in man by the Food and Drug Administration (FDA), it was considered desirable to attempt to find a product having the properties both of a contraceptive and of a prophylactic approved by the FDA in the very near future, so as to obviate long delays in placing effective products at the disposal of the public health programme. Contraceptive preparations for vaginal application are widely used and well accepted by many groups as effective birth control agents. It was thus decided to test these first for their effect on the two most frequently occurring venereal disease organisms, the gonococcus and $T$. pallidum.

The pathogenic treponemata are very delicate micro-organisms and require a special microenvironment for survival. Any preparation with spermicidal activity might be expected to have spirochaeticidal effect, and the results reported in this study indicate that many contraceptives available in the market have spirochaeticidal effect to various degrees, at least as judged by immobilization of the micro-organisms in vitro. Many non-contraceptive preparations also showed spirochaeticidal properties by this criterion.

Whether these immobilized treponemes are still infectious or not, can only be answered by studies in vivo. The studies in vitro reported here may not simulate the situation in vivo, but it is possible to compare the relative effectiveness of various test samples for their effect on motility. Testing in vitro is a fast and, within limits, a reliable method for screening a large number of test samples. It is planned that the selected preparations will be tested in vivo on rabbits. Similar techniques were used in the study of the prophylaxis of syphilis and were eventually accepted in the development of a highly effective preparation, Orvus-Mapharsen solution, to prevent syphilis (Arnold and Cutler, 1956; Arnold and Mahoney, 1948).

Unfortunately there is no readily available animal model for conducting such experiments to study gonococcal infection. However, two types of tests to determine bactericidal or bacteriostatic effects as reported in this study can be used to select the preparations which are more effective for inhibiting the growth of $N$. gonorrhoeae and which may then be considered for clinic study. The concentrations of various preparations which effectively inhibit the growth of $N$. gonorrhoeae as found by such studies are relative values and should by no means be considered the absolute effective value of these products. Nevertheless, under similar experimental conditions, the results are reproducible and were used to compare minimum inhibitory concentration (MIC) and or minimum lethal concentration (MLC) of these contraceptive and non-contraceptive preparations. The preparations which were effective by the time-exposure techniques were also effective by the plate dilution method. The differences in effective concentration by the two types of tests are due to various factors such as solubility, compatibility, stability, thermo-lability, the $p \mathrm{H}$ of the medium, and the bacteriostatic or bactericidal properties of the test samples.

The exposure to changes in $\mathrm{pH}$ alone in the range of 3.0 to 10.5 up to 10 minutes before streaking was not found to inhibit the growth of gonococci. The role of the $p \mathrm{H}$ in the viability of gonococci will be studied further by more quantitative techniques. 
Recent studies showed that the commonest causes of vaginal discharges were Trichomonas vaginalis and Candida albicans (Catterall, 1970). The possible implication of these and other sexually transmissible diseases in regard to pregnancy, fertility, or the development of cervical cancer should be considered (Willcox, 1970). The role of immunization as a possible method to prevent such sexually transmitted diseases is under study. However, local chemical or drug prophylaxis might well be found effective in preventing the transmission of certain of these and other genital infections as well as of the common venereal diseases.

It is postulated that a product which simultaneously prevented both conception and a wide variety of different genital infections would be a most valuable adjunct to the existing Public Health measures. It would fit into the family planning and V.D. control programmes existing in most national health services. These preliminary studies are encouraging, and further work along these lines is in progress.

\section{Summary}

Twenty vaginal contraceptive preparations and seventeen other compounds, mostly vaginal antiseptics, were studied in vitro for their effect on the motility of virulent $T$. pallidum and were also tested for their bactericidal or bacteriostatic effects on Neisseria gonorrhoea. Concentrations of several contraceptives and other preparations as low as 1 per cent. were effective in immobilizing spirochaetes in suspension within 1 to 1.5 minutes. Similarly, several products inhibited gonococcal growth as shown by time-exposure as well as plate-dilution techniques. These results in vitro are reported. Further studies in vitro and in vivo are in progress to find the preparations which show the greatest potential for topical use in V.D. prophylaxis and contraception.

Our thanks are due to Dr. Monto Ho, Head of the Department of Epidemiology and Microbiology, for his encouragement and advice, to Dr. Robert B. Yee for helpful suggestions, and to other members of the Pro-Con Project for their assistance.

This work was carried out under Contract No. AID csd/2822. Funded by the Agency for International Development.

\section{References}

American Social Health Association (1969) 'Today's V.D. Control Problem'. A.S.H.A., New York
ARnold, R. C., and CutLeR, J. C. (1956) Brit. f. vener. Dis., 32, 34

and MAHONEY, J. F. (1948) F. vener. Dis. Inform., 29, 138

CATtERAll, R. D. (1970) Brit. F. vener. Dis., 46, 122

Cutler, J. C., Utidjian, H. M. D., Singh, B., and ARNolD, R. C. 'Studies on Development of a Vaginal Preparation Providing Both Prophylaxis Against Venereal Disease, Other Genital Infections, and Contraception. I. Venereal Prophylaxis, Past Experience, Present Status and Plans for Future Studies' (1971) Milit. med. (in press)

IDsøE, O., and GuTHE, T. (1967) Brit. f. vener. Dis., 43, 227

Kraus, S. J., and WeBster, B. (1971) 'Diagnosis of Gonorrhoea'. Pfizer Laboratories Division, Pfizer Inc., New York

ThAYER, J. D. (1970) In 'Manual of Clinical Microbiology', ed. J. E. Blair, E. H. Lennette, and J. P. Truant, pp. 82-87, American Society for Microbiology, Bethesda, Maryland

TURNER, T. B., Hollander, D. H., and SCHAEFFer, K. (1953) Bull. Wld Hlth Org., 8, 7

U.S. FOOD AND DRUg ADMINISTRATION (1931) 'Methods of Testing Antiseptics and Disinfectants'. Circular No. 198. U.S. Department of Agriculture, Washington

WEBSTER, B. (1970) Brit. F. vener. Dis., 46, 406

Willcox, R. R. (1970) Abstr. Hyg., 45, 993

Sur une préparation vaginale assurant à la fois la prophylaxie des maladies vénériennes et des autres infections génitales et la contraception

II. Effet in vitro de préparations vaginales

contraceptives et non contraceptives sur

Treponema pallidum et Neisseria gonorrhoeae

SOMMAIRE

Vingt préparations vaginales contraceptives et dix-sept autres composés, principalement des antiseptiques vaginaux, ont été étudés in vitro sur la mobilité du $T$. pallidum virulent et éprouvés aussi pour leur effet bactéricide ou bactériostatique sur Neisseria gonorrhoeae. A des concentrations aussi faibles que 1 pour cent, plusieurs contraceptifs et d'autres préparations immobilisèrent les spirochètes en suspension en 1 à 1,5 minute. De même, plusieurs produits inhibèrent la pousse du gonocoque, comme ceci fut montré par la durée de contact nécessaire ou la technique des dilutions sur plaques. Ces résultats in vitro sont rapportés. Des études ultérieures, in vitro et in vivo, sont en cours pour trouver les préparations se montrant les plus puissantes en emploi local pour la prévention des maladies vénériennes et la contraception. 


\section{APPENDIX}

Names and Sources of Contraceptive and Non-contraceptive Preparations Tested

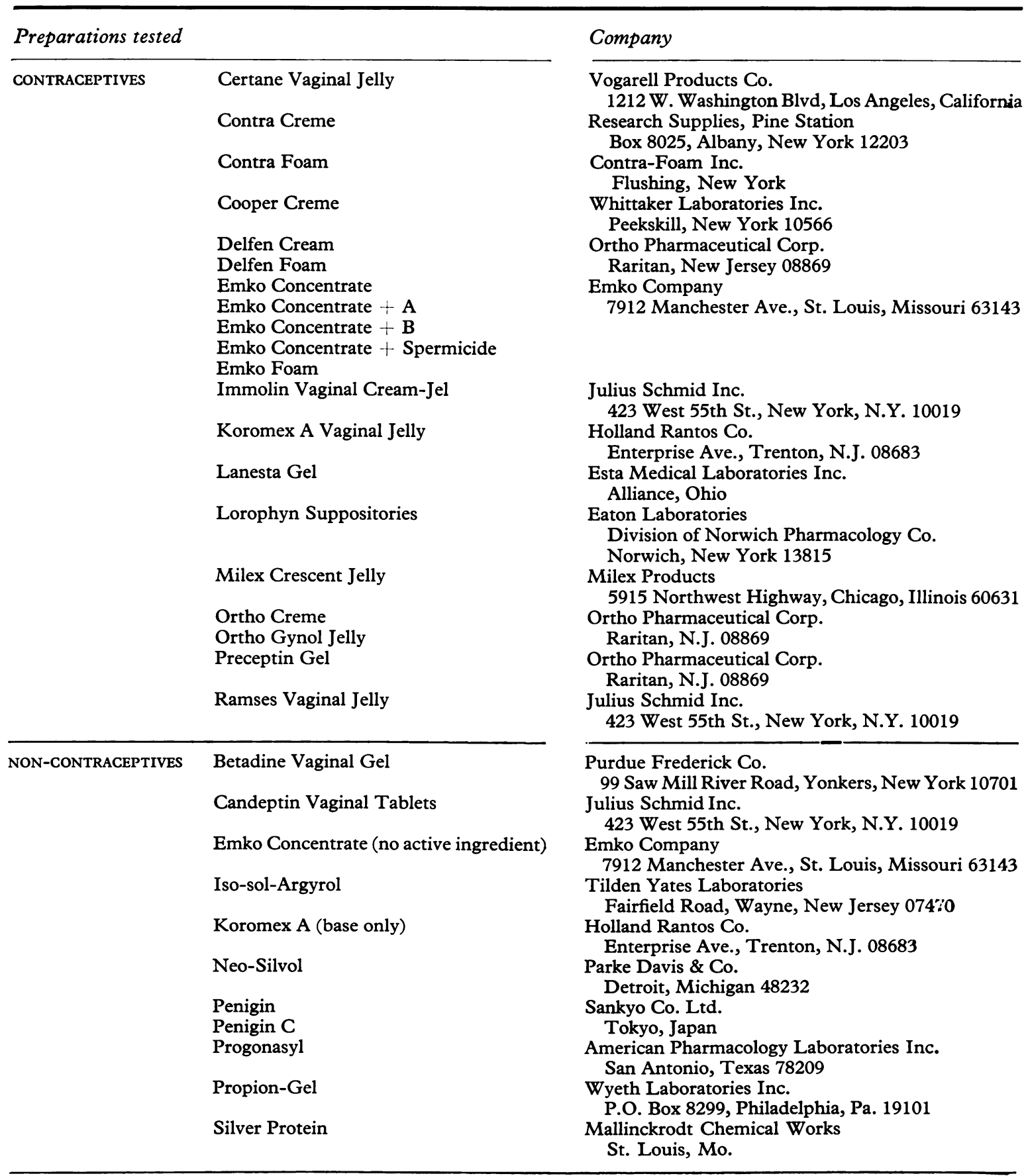


Sporostacin Vaginal Cream

Trib Vaginal Cream

Trimo San Vaginal Jelly

Vabal D Base

Vagisec Liquid Douche
Ortho Pharmaceutical Corp.

Raritan, N.J. 08869

Roche Laboratories

Division of Hoffman La Roche Inc.

Nutley, N.J. 07110

Milex Products

5915 Northwest Highway, Chicago, Ill. 60631

Semed Pharmaceuticals

Division of S.E. Massengill Co.

Bristol, Tenn. 37620

Julius Schmid Inc.

423 West 55th St., New York, N.Y. 10019 